\title{
OUTCOME OF INTERNAL FIXATION OF METACARPAL FRACTURES OF HAND AT A TERTIARY GARE HOSPITAL, KATHMANDU
}

\author{
Shrestha $P^{1}$, Paudel SR ${ }^{2}$, Chalise $P^{1}$
}

${ }^{1}$ Department of Orthopedics, Nepal Medical College Teaching Hospital, Attarkhel, Gokarneshwor-8, Kathmandu, Nepal, ${ }^{2}$ Department of Orthopedics, Scheer Memorial Adventist Hospital, Banepa, Kavre, Nepal

\begin{abstract}
Hand fractures are different from other fractures elsewhere in the body. Functional impairment of hand leads to a prominent issue to the patient. We have a common practice of treatment of hand fractures by using kirschner wire(s). The internal fixation using plates and screws for metacarpal fractures of the hand is technically demanding but it is beneficial to the patients as it permits early mobilization and better pain relief. We studied the outcome of this type of internal fixation of the metacarpal fractures at Nepal Medical College. We included 26 patients above 18years with isolated extraarticular, closed and open Swanson I metacarpal fractures of the hand. Fractures with rotation of the digit and unacceptable angulation, shortening and unstable fractures were included. Pain was evaluated by visual analogue scale and function using American Society for Surgery of hand Total Active Flexion (ASSHTAF) score. The mean pain score (VAS) was 0.27 at 12 weeks. The ASSHTAF score showed excellent results in $92.3 \%$ patients at 12 weeks. At the final follow up $92.3 \%$ patients had excellent results, $3.8 \%$ had good and $3.8 \%$ had poor results. Fracture union was seen in all patients at final follow up. The study shows that internal fixation of unstable metacarpal fractures gives significant pain relief to the patient and an excellent functional outcome.
\end{abstract}

\section{KEYWORDS}

Functional outcome, internal fixation, metacarpal fractures

\section{CORRESPONDING AUTHOR}

Dr. Praphulla Shrestha,

Lecturer, Department of Orthopedics,

Nepal Medical College Teaching Hospital,

Attarkhel, Gokarneshwor-8, Kathmandu, Nepal

Email: praphulla_sh@yahoo.com 


\section{INTRODUCTION}

Hand fractures differ from fractures elsewhere in the body due to peculiar anatomy and function of the hand. Functional impairment may follow seemingly minor trauma from resultant sensory loss, motion restriction and weakness. ${ }^{1}$ The principles of management of hand fractures include the attainment of anatomical (or near-anatomical) position, adequate stability to allow both fracturehealing and early active digital motion. ${ }^{2}$ Fracture fixation needs to be strong enough to immobilize the fracture until the strength of the healing callus surpasses that of the fixation. Early mobilization helps to prevent adjacent tendon and joint adhesions, stiffness and achieve desired range of movement at the joint. Anatomical reduction and stable fixation help to control and minimize pain and are instrumental in permitting the early active range-of-motion exercises that are the cornerstone of rehabilitation and recovery.

Prolonged immobilization leads to joint stiffness and dystrophy of soft tissues. The potential progression towards serious functional limitation (due to pain, instability or stiffness in hand) and the resulting significant socio-economic repercussions must be at the forefront of a surgeon's mind early on during the initial care of any finger or hand trauma. ${ }^{3}$

Ultimate functional outcome is more important than just fracture healing. ${ }^{4}$ The goal of treatment is to return patient's hand function to pre-injury level. ${ }^{5}$ For many non-displaced fractures and fractures that can be stably reduced, immobilization by buddy taping, splinting, plaster casting and molded orthoplast splints (with foam and metal) are the preferred method of treatment. ${ }^{6,7}$ But in complex injuries, it may not be suitable. Prolonged immobilization may be necessary for healing. Unfortunately, more than 3 weeks of immobilization can cause finger stiffness and tendon adhesions. While many factors outside the doctor's control, such as the amount of soft tissue and bone injury, also contribute to stiffness, every effort should be made to allow movement by 3-4 weeks after injury. ${ }^{8}$

Surgical options for fracture reduction include Krischner wires, intramedullary nailing, compression screws, external fixation, and plate and screw fixation. Compression screws and plate fixation techniques offer the greatest potential advantage for rigid fixation, allowing for earlier resumption of range of motion. ${ }^{9}$ As per Dr. Alfred Swanson, "Hand fractures can be complicated by deformity from no treatment, stiffness from over treatment and both deformity and stiffness from poor treatment.”

In spite of early mobilization, stiffness is the most frequently encountered complication, followed by wound infection, nonunion and reflex sympathetic dystrophy. ${ }^{10}$ Although, today's technology (anaesthesia, antibiotics, technologically advanced implants) allows considerable freedom in treating these injuries, still a number of patients suffer a complicated course of events and experience stiffness, nonunion, malunion, and chronic pain following hand fractures. ${ }^{11}$

Most metacarpal fractures, in our settings are inadequately treated. It has been proven by various studies conducted in developed countries that miniplates and screw fixation offers the best functional outcome. This study was conducted to evaluate the outcome of this treatment modality in our settings, which can change our clinical practice.

\section{MATERIALS AND METHODS}

This study was a prospective observational study. It was carried out in department of Orthopedics of Nepal Medical College Teaching Hospital. The study period was from April 2017 to September 2018. Twenty-six patients presenting to the emergency and outpatient department were included in the study. Patients above 18 years of age, with isolated extraarticular fractures of metacarpals, Swanson's type I open fractures were included in the study. Fractures with rotation of the digit and unacceptable angulation, shortening and unstable fractures were included. Patients with multiple fractures, fingers with amputated digits, Swanson's type II open fractures, thumb fractures, preexisting deformities of hand and medical contraindications to surgery were excluded from this study.

All pre-operative work-up were done, written and informed consent was obtained from the patients regarding surgery and their inclusion in this study. The required information was recorded in the proforma. Patients were taken for surgery as soon as possible. Surgeries were performed in a standard manner and plates were applied on the dorsal surface of the bone.

The hand was elevated on a sling for 24-48 hours to control pain and swelling. The wound was inspected after 48 hours. The hand was mobilized actively thereafter. Post-operative check x-ray was done. Active finger movement was encouraged within the limits of pain and patient was discharged.

Follow up of the patients were done at 2 weeks, 6 weeks and 12 weeks. Stitches were removed at 2 weeks follow up. Fracture union was monitored by clinical and radiological criteria on each follow up. Absence of pain on movement of adjacent joints; and absence of tenderness over the fracture site on palpation was considered clinical criteria for union. Radiological union was considered when the fracture line was obliterated in three of the four cortices. $^{12,13}$

Clinical progress in terms of range of movement, relief of pain (Visual Analog Scale) and complications was recorded at each outpatient visit. The final range of motion of operated finger was noted in degrees.

ASSHTAF (American Society for Surgery of Hand Total Active Flexion) score was calculated. This was done 
by adding the active flexion at metacarpophalangeal, proximal interphalangeal and distal interphalangeal joints, after subtracting the sum of extension deficit at these three joints. The normal range of digital motion is $260^{\circ} .{ }^{14}$ The ASSHTAF score grades the results as: excellent (flexion $\geq 220^{\circ}$ ); good (flexion $120^{\circ}-80^{\circ}$ ); poor (flexion $\leq 80^{\circ}$ ).

\section{RESULTS}

The mean age of our patients was 28.12 years (range 19-38 years). It was 27.4 years for males and 29.6 years for females. Forty-six of the patients $(n=12)$ were farmers. The most common mechanism of injury was road traffic accident (42.3\%), followed by physical assaults and accidents at workplace (Table-1). Twenty-two (84.6\%) were closed injuries. Second and fourth metacarpals (Fig. 1) were the most commonly fractured metacarpals in our series with $34.6 \%(\mathrm{n}=9)$ in each (Table-1). Twenty-three (88.4\%) patients had fracture on the dominant side.

\begin{tabular}{|c|c|}
\hline \multicolumn{2}{|c|}{$\begin{array}{l}\text { Table-1: Characteristics of the study } \\
\text { population and the procedure }\end{array}$} \\
\hline Particulars & Number (\%) \\
\hline \multicolumn{2}{|l|}{ Sex } \\
\hline Male & $19(73.1)$ \\
\hline Female & $07(26.9)$ \\
\hline \multicolumn{2}{|l|}{ Mechanism of injury } \\
\hline Road Traffic Accident & $11(42.3)$ \\
\hline Industrial/domestic accidents & $05(19.2)$ \\
\hline Fall from height & $03(11.5)$ \\
\hline Sports & $02(7.7)$ \\
\hline Physical assault & $05(19.2)$ \\
\hline \multicolumn{2}{|l|}{ Fractured side } \\
\hline Right & $15(57.7)$ \\
\hline Left & $11(42.3)$ \\
\hline \multicolumn{2}{|l|}{ Fractured Metacarpal } \\
\hline Second & $09(34.6)$ \\
\hline Third & $04(15.4)$ \\
\hline Fourth & $09(34.6)$ \\
\hline Fifth & $04(15.4)$ \\
\hline \multicolumn{2}{|l|}{ Type of injury } \\
\hline Closed & $22(84.4)$ \\
\hline Open & $04(15.4)$ \\
\hline \multicolumn{2}{|l|}{ Type of fracture } \\
\hline Transverse & $12(46.2)$ \\
\hline Oblique & $06(23.1)$ \\
\hline Spiral & $07(26.9)$ \\
\hline Comminuted & $01(3.8)$ \\
\hline \multicolumn{2}{|l|}{ ASSHTAF score at 12 weeks } \\
\hline Excellent & $24(92.3)$ \\
\hline Good & $01(3.8)$ \\
\hline Poor & $01(3.8)$ \\
\hline \multicolumn{2}{|l|}{ Fracture union at 12 weeks } \\
\hline United & $26(100)$ \\
\hline Non-union & $00(0)$ \\
\hline
\end{tabular}

Morphologically, transverse fractures were most common $(46.2 \%)$ followed by spiral and oblique. (Table-1). Surgical site infection was seen in $11.5 \%$ $(n=3)$ cases. The mean pain score (VAS) was 6.12 at 2 weeks, which dropped to 2.12 at 6 weeks and 0.27 at 12 weeks. The ASSHTAF score showed excellent results in $23.1 \%$ at 2 weeks, in $73.1 \%$ at 6 weeks and in $92.3 \%$ at 12 weeks. At the final follow up $92.3 \%$ patients had excellent results, $3.8 \%$ had good and $3.8 \%$ had poor results. Fracture union was seen in all patients at final follow up (Table-1). The improvement in ASSHTAF score seen at 12 weeks in comparison to the score at 2 weeks was statistically significant $(p<0.05)$ as shown by Wilcoxon Signed Ranks Test.

\section{DISCUSSION}

Most metacarpal fractures can be treated by nonoperative methods with good outcome. In the small percentage of unstable fractures, results of closed treatment are usually unsatisfactory. Indications for accurate open reduction and internal fixation in hand fractures are few, probably accounting for less than $5 \%$ of all fractures..$^{15}$ Options for fixation of metacarpal fractures include plating, lag screw fixation, percutaneous or intramedullary fixation, interosseous wiring, and external fixation.

Early mobilization is mandatory in order to prevent stiffness of capsulogenic or tendinogenic origin (caused by adhesions). Therefore, in the ideal situation, sufficient stability should be obtained for fracture healing to occur, while at the same time, a complete freedom of motion should be guaranteed for soft tissue structures in order to prevent adhesions. ${ }^{16}$

Open reduction and Internal fixation of metacarpal fracture with miniplates and screws is technically demanding with little margin of error, but has a role in unstable fractures. Based on the principles of $\mathrm{AO}$ / ASIF (association for study of internal fixation of fractures), stable fixation is possible with minimum two screws in long oblique fractures. Short oblique fractures can be fixed using 4 or 5 holed plates (mini or micro plates). Intra-articular fractures with metaphyseal extension may be fixed with condylar buttress plates. ${ }^{17}$ This allows very early return to motion. This is of particular value when fractures are associated with tendon injuries and when fractures involve multiple fingers. ${ }^{18}$ Furthermore, the incidence of non-union has been reported to be low with plate fixation. ${ }^{19}$

The demographic parameters of study population including age, sex, type of fracture and involved metacarpal were similar to other studies. ${ }^{20-23}$ The final ASSHTAF score showed excellent outcome in $92.3 \%$, which is slightly higher than reported by Chand et $a l^{23}(81.2 \%)$ and Mumtaz et al ${ }^{22}(73 \%)$.

In our series, $23.1 \%$ patients already had excellent outcome by 2 weeks and $73.1 \%$ by 6 weeks. This shows that more than two third of patients treated by 


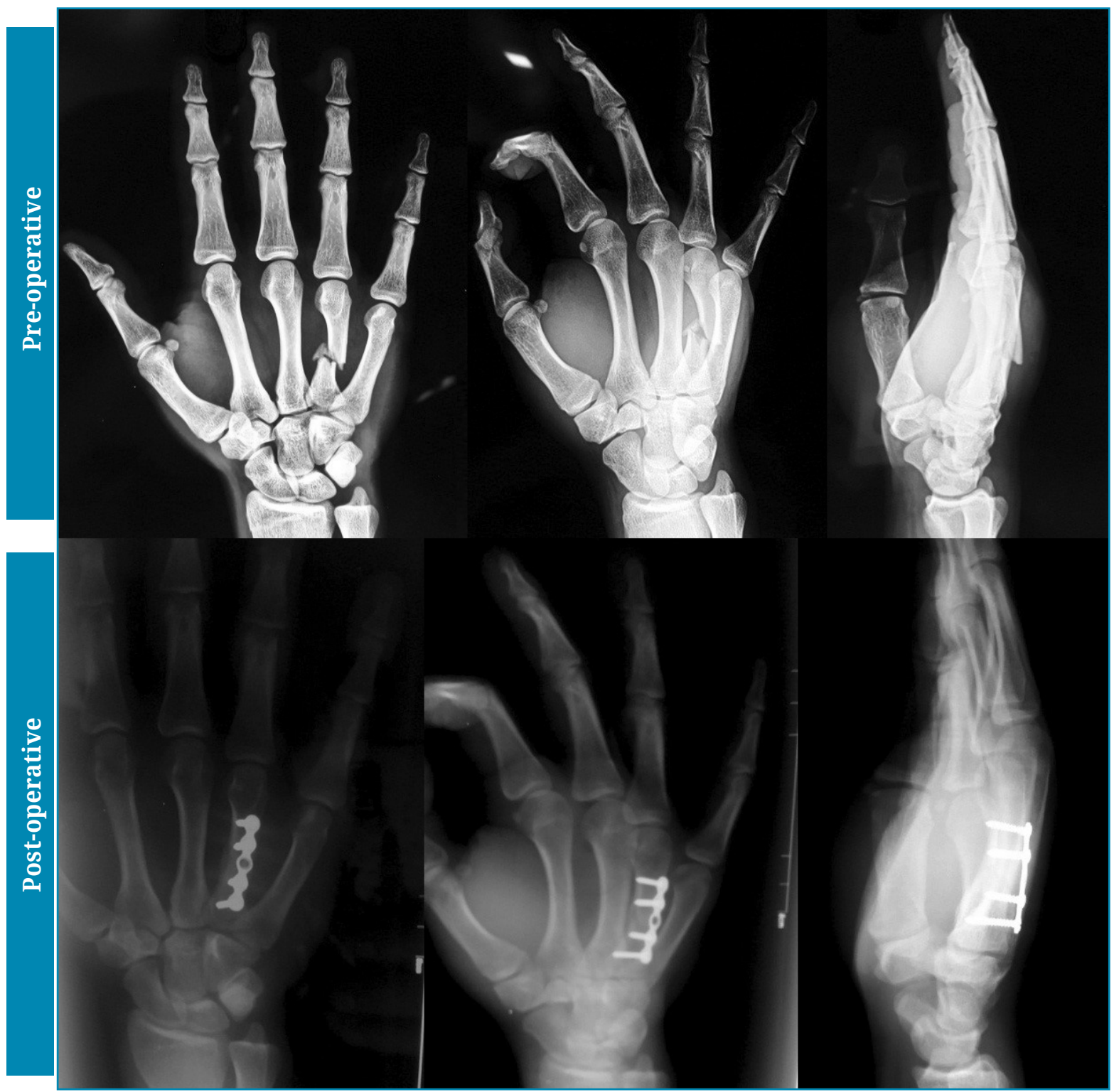

Fig. 1: Pre-operative and post-operative X-ray images of fracture shaft of $4^{\text {th }}$ metacarpal.

open reduction and internal fixation of metacarpal fractures by miniplates can go back to their normal lifestyle even before plaster or splints were removed if treated non-operatively or with Kirschner (K) wire fixation.

With improved instrumentation and equipment, better anesthesia, better soft tissue coverage techniques and therapy, hand surgeons generally have become more aggressive in the surgical management of hand fractures; however, operative stabilization cannotalways be equated withimproved outcome. Apart from surgery many other factors, including patient factors (age, associated diseases, compliance), fracture factors (location, geometry, stability, soft tissue injury, and associated injuries), and management factors (diagnosis and recognition, maintenance of reduction, immobilization time, and recognition and management of complications) affect the outcome of hand fractures. ${ }^{24}$ As noted above, most of the determinants of outcome are beyond the surgeon's control.
The incidence of surgical site infection was $11.5 \%$ in our series, which correlates with $15.4 \%$ open fractures included in the study. Complications correlate with the severity of the initial injury, with open fractures and crush injuries decreasing the potential for uneventful union. ${ }^{25}$ If the metacarpal fracture has undergone previous surgery but resulted in nonunion, malunion, or posttraumatic arthritis, its management can be particularly challenging. These fingers are usually stiff and sometimes painful. Besides the bone injury, there are usually soft-tissue problems that complicate the reconstructive efforts.

The future of hand fracture treatment lies in improving our ability to choose and properly apply appropriate treatment for the variety of patients and fractures that present, bearing in mind that each patient's perspective of an optimal outcome is different. ${ }^{11}$

In conclusion, the study shows that internal fixation 
of unstable metacarpal fractures gives significant pain relief to the patient and an excellent functional outcome. It provides stable fixation which permits pain free, early active range of motion of the adjacent joints. Early mobilization is important to prevent stiffness. Complications were frequent in open fractures and those presenting late. The limitation of this study was that only a few number of subjects were involved and did not have a control group. A prospective multicentric study, with a comparison group, involving large number of patients and longer duration of follow up is recommended.

\section{REFERENCES}

1. Feehan LM, Sheps SB. Incidence and demographics of hand fractures in British Columbia, Canada: a population-based study. J Hand Surg 2006; 31: 1068 -74 .

2. Hall RF, Jr. Treatment of metacarpal and phalangeal fractures in noncompliant patients. Clin Orthop Relat Res 1987; 214: 31-6.

3. Le Nen D. Extra-articular fractures of the digital metacarpals and phalanges of the long fingers. Chir Main 2014; 33: 1-12.

4. Brennwald J. Bone healing in the hand. Clin Orthop Relat Res 1987; 214: 7-10.

5. Freeland AE, Geissler WB, Weiss AP. Surgical treatment of common displaced and unstable fractures of the hand. Instr Course Lect 2002; 51: 185-201.

6. Pun WK, Chow SP, So YC, Luk KD, Ip FK, Chan KC, et al. A prospective study on 284 digital fractures of the hand. J Hand Surg Am 1989; 14: 474-81.

7. Yan YM, Zhang WP, Liao Y, Weng ZF, Ren WJ, Lin J, et al. Analysis and prevention of the complications after treatment of metacarpal and phalangeal fractures with internal fixation. Zhongguo Gu Shang 2011; 24: 199-201.

8. Strickland JW, Steichen JB, Kleinman WB. Phalangeal fractures: factors influencing digital performance. Orthop Rev 1982; 11: 39-50.

9. Jabaley ME, Freeland AE. Rigid internal fixation in the hand: 104 cases. Plast Reconstr Surg 1986; 77: 288-98.

10. Kurzen P, Fusetti C, Bonaccio M, Nagy L. Complications after plate fixation of phalangeal fractures. J Trauma 2006; 60: 841-3.

11. Harness NG, Meals RA. The history of fracture fixation of the hand and wrist. Clin Orthop Relat Res 2006; 445: 19-29.

12. Morshed S. Current Options for Determining Fracture Union. Adv Med 2014: 708574,2014.

13. Charnley J. The closed treatment of common fractures: Cambridge: Cambridge University Press; 1999.

14. Singh AK, Narsariya N, Arun GR, Seth RRS. Outcome of Displaced Metacarpal and Proximal Phalangeal Fractures Treated with Intramedullary K wire and Cross k-wires: A Prospective Study of 105 Patients. Int'l J Orthop 2014; 1: 25-30. Soni A, Gulati A, Bassi JL, Singh D, Saini UC. Outcome of closed ipsilateral metacarpal fractures treated with mini fragment plates and screws: a prospective study. J Orthop Traumatol 2012; 13: 29-33.
15. Freeland AE, Jabaley ME, Hughes JL. Stable fixation of the hand and wrist. New York: Springer-Verlag, 1986: 55

16. Kamath JB, Harshvardhan, Naik DM, Bansal A. Current concepts in managing fractures of metacarpal and phalangess. Indian J Plast Surg 2011; 44: 203-11.

17. Klein DM, Belsole RJ. Percutaneous treatment of carpal, metacarpal, and phalangeal injuries. Clin Orthop Relat Res 2000; 375: 116-25.

18. Puckett CL, Welsh CF, Croll GH, Concannon MJ. Application of maxillofacial miniplating and microplating systems to the hand. Plast Reconstr Surg 1993; 92: 699-707.

19. Page SM, Stern PJ. Complications and range of motion following plate fixation of metacarpal and phalangeal fractures. J Hand Surg Am 1998; 23: 82732 .

20. Omokawa S, Fujitani R, Dohi Y, Okawa T, Yajima H. Prospective outcomes of comminuted periarticular metacarpal and phalangeal fractures treated using a titanium plate system. J Hand Surg Am 2008; 33: 857-63.

21. Mumtaz MU, Farooq MA, Rasool AA, Kawoosa AA, Badoo AR, Dhar SA. Unstable metacarpal and phalangeal fractures: treatment by internal fixation using AO mini-fragment plates and screws. Ulus Travma Acil Cerrahi Derg 2010; 16: 334-8.

22. Chand P, Thapa B, Joshi A. Early Experience with Low Profile Plate Osteosynthesis for Metacarpal Fractures. J Nepal Health Res Counc 2009; 7: 19-24.

23. Strickland JW, Steichen JB, Kleinman WB, Hastings $\mathrm{H}$ II, Flynn N. Phalangeal fractures: factors influencing digital performance. Orthop Rev 1982; 11: $39-50$.

24. Bannasch $\mathrm{H}$, Heermann AK, Iblher N, Momeni A, Schulte-Monting J, Stark GB. Ten years stable internal fixation of metacarpal and phalangeal hand fractures-risk factor and outcome analysis show no increase of complications in the treatment of open compared with closed fractures. J Trauma 2010; 68: 624-8. 